\title{
How Marketing Factors Influence Online Browsing and Sales: Evidence From China's E-Commerce Market
}

\author{
Zheng Wang, SungKyunKwan University, South Korea
}

Yongjune Kim, SungKyunKwan University, South Korea

\begin{abstract}
As the e-commerce market evolves from being primarily transactional to being more subtle, sellers now seek to form online strategies. Previous studies have investigated buyers' purchasing patterns, online transaction trust, electronic word-of-mouth, online resale behavior as well as online auctions. However, less is known about the antecedents that effect store traffic and sales. By using real market data from a major Chinese C2C e-commerce site, this article investigates C2C transactional formation and identifies sellers' performance payoffs that result from various marketing factors. Marketing factors that influence store traffic and sales will be analyzed by means of the Negative Binomial model and Tobit model. Results point out that strong store reputation and high service quality are crucial indicators for increasing number of browsers and sales amount. In accordance with the results of prior research, advertising is confirmed as an effective tool for positively influencing both store traffic and sales. In addition, we found that guarantee policies can positively impact store sales only by interacting with reputation ratings. Drawing on empirical findings, we also discuss the managerial implications for $C 2 C$ sellers and put forth some recommendations.
\end{abstract}

Keywords: China C2C E-Commerce; Store Traffic and Sales; Online Store Service; Online Reputation

\section{INTRODUCTION}

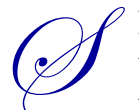

hopping on e-commerce marketplaces such as Amazon and Alibaba is experiencing tremendous growth and warrants business researchers' attention. In the United States, more than $60 \%$ of buyers make e-commerce purchases through online marketplaces, and online retail sales are expected to exceed $\$ 330$ billion in 2015 (Forrester Report, 2015). The Chinese Internet Network Information Center (CNNIC) states that the engagement with online platforms for business has experienced the highest rate of growth among Chinese netizens (CNNIC, 2015), leading the growth of the online retail market as a whole. Additionally, there has been an emergence of several new e-commerce patterns. The consumer-to-consumer (C2C) e-commerce pattern, for example, has experienced a growth in usage by both buyers and sellers in the market (Jones \& Leonard, 2014).

A growing body of $\mathrm{C} 2 \mathrm{C}$ e-commerce studies has investigated buyers' purchasing pattern (Bellman, Lohse \& Johnson, 1999; Chen \& Barnes, 2007; Xu, Lin \& Shao, 2010), online transaction trust (Chen, Zhang \& Xu, 2009; Chow \& Angie, 2006; Jones \& Leonard, 2014; Wu, Vassileva, Noorian \& Zhao, 2015), electronic word-of-mouth (HennigThurau \& Walsh, 2003), online resale behavior (Chu \& Liao, 2008), as well as online auctions (Vishwanath \& Barnett, 2005; Stafford \& Stern, 2002; Ward \& Clark, 2014; Amyx \& Luehlfing, 2006). Store traffic and sales serve as major drivers of online business performance, and therefore are essential variables of interest for marketing managers. Nevertheless, only a few works have done empirical studies of these two variables. This article aims to contribute to the analysis of China's e-commerce market by examining how various antecedent marketing factors effect store traffic and sales.

We have selected four major marketing factors that mainly influence store traffic and sales volume in the ecommerce. We focus on store advertising, service quality, guarantee policies, as well as store reputation. In previous research, the focus was on the influential role of marketing factors on store sales volume. However, most studies only assessed the 
separate effect using survey method by focusing on one or two variables. Our research will analyze the joint effects of all factors at the store level, paying particular attention to real market data from a major Chinese $\mathrm{C} 2 \mathrm{C}$ e-commerce site. The results of this article will help individual sellers to assess and improve their existing strategies to attract more customers and will help people have an insight on business activities of Chinese ecommerce market.

This article's format is as follows: After analyzing pertinent literature, we will discuss the main theoretical hypotheses. In order to fully comprehend the distinct effects of antecedent factors on store traffic and store sales, we then present Negative Binomial model and Tobit model. Afterwards, we present our empirical results and discussion.

\section{CONCEPTUAL DEVELOPMENT}

\section{Store Traffic}

Store traffic refers to the amount of circulation the store receives, in other words, the number of browsers that visited in the store. In the prior studies, store traffic is regarded as a significant indicator of store performance due to the logic that increased traffic implies more opportunity to sell (Gijsbrechts, Campo \& Goossens, 2003; Babakus, Bienstock \& Scotter, 2004). In the context of e-commerce, store traffic includes two types of browsers: directed browsers and exploratory browsers. Directed browsers can be defined as directed buyers with a specific object for consumption, or visitors who are already searching for a certain category of product (Zhao, Sun \& Su, 2012). On the other hand, exploratory browsers can be recognized as one of two types. The first includes browsers who are not seeking a specific product or type of product but may still impulsively purchase goods. The second includes browsers who only search for information but are not looking to purchase goods. (Moe, 2003). The main difference between directed browsers and exploratory browsers is that the former is motivated by purchases but the latter is typically not (Zhao et al. 2012). Thus, different marketing factors would have different impacts on the two types of browsers.

In addition, a crucial issue for marketers is how to convert store browsers into customers that make purchases by attracting the browsers into the marked point process of sales. With simpler search and smaller costs for search online, the conversion for directed browsers becomes easier (Cachon, Terwiesch \& Xu, 2008); while exploratory browsers can transform states from browsing to purchasing as the regularity of browsing grows deeper (Montgomery, $\mathrm{Li}$, Srinivasan \& Liechty, 2004; Bucklin \& Sismeiro, 2003). Accordingly, previous studies have demonstrated that a variety of services, advertising, in-store promotions, product selection, as well as quality improvement programs are effective strategies to generate an incremental raise in traffic and stimulate sales in the offline stores (Pan \& Zinkhan, 2006; Gijsbrechts et al. 2003). Because marketing activities may have different effects on the conversion of customers' online browsing behavior towards sales, in this article, instead of observing store traffic as a precursor to sales, we investigate it as a dependent variable for store performance.

\section{Marketing Activities on Store Traffic and Sales}

Drawing on previous research and practical considerations, multiple marketing variables that can impact store traffic and sales are considered in this study.

\section{Advertising}

As an online communication tool, advertisement is considered a direct and effective way to appeal to visitors (Wu et al., 2016). In the $\mathrm{C} 2 \mathrm{C}$ business, sellers often use two advertising formats in their selling campaigns to target consumers with product-based messages and price incentives. These include static banners that offer static images of a fixed size, or dynamic banners that offer animation but no interactivity. A buyer may initially have to rely on the outward appearance of banner and product advertisement. It especially works well on browsers who have a purchase goal or a general product category in mind when the advertising is obviously related to their objectives. A large body of work on online advertising has suggested that the effects of advertising messages may vary according to the presenting size, animation, and contents (e.g. Bruce, Murthi \& Rao, 2017), because these deliver different information to customers. Since most of the ads in $\mathrm{C} 2 \mathrm{C}$ stores are banners that are similar in format, we want to know how advertising effects may differ if control for other covariates. In other words, we want to figure out the effects of advertising by jointly 
assessing the effects of store service, reputation and guarantee policies. Knowing these results could help store sellers better allocate limited resources throughout their e-commerce campaigns.

A common view about advertising is that it benefits the sellers because it makes consumers aware of the advertised product. Research has also proposed other informative and persuasive effects of advertising that increase the chances of consumers choosing the advertised option over other options (Sahni, 2016). However, regardless of how much benefit the advertising strategy possesses, high expenditure on advertising is a heavy financial burden for individual sellers in the $\mathrm{C} 2 \mathrm{C}$ business, making it so that relatively few sellers can afford to make the expense. To what extent can advertisement influence store traffic and sales? Are the payoffs worthy? The effect of $\mathrm{C} 2 \mathrm{C}$ advertising is of interest to us here, and we project that:

H1: Advertising has a positive effect on (a) store traffic, and (b) store sales.

\section{Service}

Service quality is a crucial differentiator in e-commerce environment. $\mathrm{C} 2 \mathrm{C}$ transaction generally consists of buyers and sellers who are transacting with each other for the first time. The buyer typically does not have sufficient information about the seller's history, goods, and services. If the seller can promptly reply to the buyer's inquiries or problems and can deliver the product or service within a reasonable time frame, it gives the buyer a sense that the seller's products and services are reliable and safe. Consequentially, the buyer will exhibit higher satisfaction and will have the desire to purchase again in this store. Previous studies have indicated consumer satisfaction resulting from the buyer's perception and evaluation of the seller's service quality (Anderson \& Srinvasan, 2010; Deng, Zheng \& Qin, 2014), and have demonstrated the positive impact of service quality on consumers' behavior intentions and loyalty (Deng et al., 2014; Udo, Bagchi \& Kirs, 2010), but there is still a lack of proper investigation of the direct relationship between store traffic (and thus, sales) and quality of service. For $\mathrm{C} 2 \mathrm{C}$ business, delivering high service quality is a competitive strategy for individual sellers to obtain customer satisfaction, trust, commitment and favorable intentions, as well as to reduce uncertainty during the transaction process. In addition, reliable service can narrow the psychological distance between buyers and sellers, consequently increasing customer satisfaction. Therefore,

$\mathbf{H}_{2}$ : The better service quality a store has, the more likely there will be an increase in (a) store traffic, and (b) store sales.

\section{Guarantee Policies}

During the $\mathrm{C} 2 \mathrm{C}$ transaction process, the buyer carries the risk of paying for services and goods before receiving them. Accordingly, a challenge for sellers is maintaining dedication to service quality and the satisfaction of their customers even after customer expectations are not met (Boshoff \& Staude, 2003). It is necessary to have strategies to recover from such an obstacle because customers will be much more likely to switch to a different firm (Forbes, Kelley \& Hoffman, 2005). In the context of the online market, switching is significantly easier because alternative options are much simpler to find. Consequently, store guarantee policies are particularly relevant for customer loyalty, and have a high indication of whether customers will purchase or repurchase in the store. Moreover, a salient guarantee policy is a fundamental aspect of trust for online business; it has the potential to sway buyers in making a purchase decision. The guarantee policy often influences the buyer's decision in choosing one seller over another (Karimov \& Brengman, 2014). The salience of a seller's guarantee policy manifests in the customer's level of trust in the quality of the seller's products. (Karimov \& Brengman, 2014). Thus, guarantee policies are an imperative competitive tool in increasing sales for a longer period of time in the $\mathrm{C} 2 \mathrm{C}$ transaction.

Furthermore, based on signaling theory, the primary job of guarantee policies is to inform buyers of the seller's continued commitment to buyers after the transaction is completed. For example, the return policy guarantee promises to compensate the buyer if the product is not of good quality or does not satisfy the buyer's expectations. If a buyer cannot have such information, he/she will perceive the transaction as too risky (Bower \& Maxham, 2012) and will have a higher switch intention (Forbes et al. 2005). Thus, we assume that,

H3: Guarantee policies have a positive effect on (a) store traffic, and (b) store sales. 


\section{Store Reputation}

Like service quality and guarantee policies, store reputation is another signal of a seller's quality, as perceived by customers (Melnik \& Alm, 2002). The store reputation serves as a source of information since a strong reputation can alleviate buyers' perceived risk and potential concerns about the seller (Pavlou, Liang \& Xue, 2007). In the C2C transactions, a signal of a seller's reputation provides a viable mechanism for fostering trust and reliability among unknown buyers by ensuring them that the behavior of the seller toward any other buyers may be publicly known and in turn, will affect other customers' evaluation or judgment of the seller in the future (Dellarocas, 2003). This indicator typically is easily accessible and highly visible in the front page of a store (e.g., hearts or diamonds to rate the seller). Accordingly, most of online shoppers are influenced by others' perceptions of seller quality, which signal credibility and thereby reduce perceived uncertainty (Anderson, Swaminathan \& Mehta, 2013). Thus, we expect that customers seek out sellers that have strong reputations, and we assume that,

H4: The stronger reputation a store has, the more likely there will be an increase in (a) store traffic, and (b) store sales.

In contrast to the browsing behavior, more deliberateness takes place when customers intend to make a purchase decision. That is to say, to keep building the consideration set and evaluating the ready-to-buy options, buyers are often dedicated to seeking out more information so as to reason out their purchasing choices. As an indicator for mitigating information asymmetry of $\mathrm{C} 2 \mathrm{C}$ transactions, seller's reputation is commonly calculated by prior buyers' ratings and reviews. This relatively objective reputation evaluation system can enable trust (Resnick, Zeckhauser, Friedman \& Kuwabara, 2000), and serves its purpose by allowing the reputation to be seen by any potential buyers. In some cases, the high reputation indicates a high level of seller trustworthiness (Ba \& Pavlou, 2002), accurate product descriptions (McDonald \& Slawson, 2002), and better services (McDonald \& Slawson, 2002). If the product quality cannot be confirmed, a trusted seller experiences substantial advantage prior to the purchase. We expect that when the seller is perceived as having a stronger reputation, versus a weaker reputation, two informational signals about the seller (i.e., seller's service quality and store guarantee policies) have more impact and are more valuable to the buyers when they make purchasing decisions. Thus,

H5: The positive effect of (a) store service, and (b) store guarantee policies on sales is greater in cases of higher reputation, versus lower reputation levels cases.

\section{RESEARCH METHODOLOGY}

\section{Data}

We test the hypotheses using real transactional data provided by one of the largest $\mathrm{C} 2 \mathrm{C}$ e-commerce platforms in China. This cross-sectional data set contains store traffic and sales data for cosmetic products on a randomly given week of June 2014. Through preliminary data screening, we deleted 45 observations with missing values, and ruled out 62 stores without any transactions during the period under the criteria if store total sales amounted to zero and store service score equaled $15^{\mathrm{i}}$. The final dataset consists of 760 stores in the cosmetic products category.

\section{Measures}

The key dependent variables are store traffic and sales. Store traffic (ST) is the total number of people who browsed the store in the week. It is measured by a count of customers who clicked and browsed the store web page, except those who only browsed the item or product via searching pages. In terms of store sales (SS), we use total weekly selling amount for its measurement.

Advertising $(A D)$ is estimated by the advertisement expenses that sellers have spent on the store. Store service quality $(S Q)$ ratings include three aspects, namely, description consistence, service attitude, and logistics speed. Each of them scores $0-5$ points. We use sum of the three sub-dimension scores for measuring the service quality. Each seller of the platform is encouraged to sign the guarantee of trade safety agreement which ensures that he/she commits to provide guaranteed transaction service to buyers. Buyers are able to request for refund if they receive any incorrect goods. The terms of guarantee include 7 days of unconditional return, triple refund for counterfeits, and express delivery. We code 
1 if a store has one guarantee policy and 0 otherwise, and we sum the dummy points for measuring guarantee policies $(G P)$. In terms of store reputation $(R P)$, buyers have the opportunity to assess seller's performance with a 1 (positive), or a 0 (neutral), or a -1 (negative) after a successful transaction. We measure seller's reputation as a cumulative level score and calculate it as the number of buyers who gave the latest positive feedback minus the number of those who gave the latest negative feedback. For a short statement, the calculation is only one for each buyer and no matter the times of transaction that happens to the identical users. It ranges from 0 to 20 points, and the higher the level is, the stronger reputation the store has. In addition, we control for the number of items (NI) in the store in our models. Variable descriptions and correlations are presented in Table 1.

Table 1. Descriptive Statistics and Correlation Matrix

\begin{tabular}{|c|c|c|c|c|c|c|c|c|c|c|c|}
\hline Variable & M & SD & Min & Max & 1 & 2 & 3 & 4 & 5 & 6 & 7 \\
\hline 1. ST & 659.40 & 2302.96 & 1 & 41739 & 1.00 & & & & & & \\
\hline 2. SS & 2158.85 & 8306.40 & 0 & 160988 & 0.72 & 1.00 & & & & & \\
\hline 3. $\mathrm{AD}$ & 1726.94 & 13406.70 & 0 & 312440 & 0.14 & 0.38 & 1.00 & & & & \\
\hline 4. SQ & 14.52 & 0.34 & 11.22 & 15 & -0.03 & -0.07 & -0.08 & 1.00 & & & \\
\hline 5. GP & 1.13 & 0.97 & 0 & 3 & 0.07 & 0.08 & 0.08 & -0.12 & 1.00 & & \\
\hline 6. RP & 7.55 & 2.93 & 0 & 14 & 0.27 & 0.34 & 0.16 & -0.28 & 0.37 & 1.00 & \\
\hline 7. NI & 392.58 & 550.39 & 1 & 8607 & 0.16 & 0.21 & 0.03 & -0.12 & 0.16 & 0.34 & 1.00 \\
\hline
\end{tabular}

Notes: $\mathrm{ST}=$ store traffic, $\mathrm{SS}=$ store sales, $\mathrm{AD}=$ advertising expenses, $\mathrm{SQ}=$ service quality, $\mathrm{GP}=$ guarantee policies, $\mathrm{RP}=$ reputation, and $\mathrm{NI}=$ number of items in the store. Correlations that are statistically significant at $5 \%$ level are in bold. Variables 1 and 3 are in yuan of C.N. RMB.

\section{Models and Estimation Procedure}

We use natural log-transformation of the store sales to normalize the distribution of the dependent variable. We also log-transformed advertising expenses and number of items in store for coefficient preview purpose.

\section{Store Traffic Model}

The ST dependent variable, measured as the number of browsers, is a count variable. While Poisson regression can be used to model count data, the overdispersion of our data violates the essential aspect of the regression assumption that variance of the count variable must equal its conditional mean. Instead, we used a Negative Binomial regression model that mixes Poisson and Gamma distribution by incorporating individual, unobserved effects into the conditional mean (Jerry, Bronwyn \& Griliches, 1984; Long, 1997). The basic model is

$$
\begin{aligned}
\log \left(\mu_{i}\right) & =\beta X i \\
& =\beta_{0}+\beta_{1} A D_{i}+\beta_{2} S Q_{i}+\beta_{3} G P_{i}+\beta_{4} R P_{i}+\beta_{5} N I_{i}
\end{aligned}
$$

Where $\mu_{\mathrm{i}}$ stands for the mean, $X_{i}$ is a vector of explanatory variables for store $i$, and $\beta$ is a vector of estimated parameters associated with $X_{i}$. $\beta_{0}$ is the intercept, $\beta_{1} \sim \beta_{5}$ are the variable parameters respectively. Because our data shows that the mean and variance of browsers visiting a store are not equal, it violates the nature of the Poisson distribution. Therefore, an error term needs to be introduced to diffuse the issue. Thus,

$$
\begin{aligned}
& \log \left(\mu_{i}\right)=\beta X_{i}+\varepsilon_{i} \\
& \mu_{i}=\exp \left(\beta X_{i}+\varepsilon_{i}\right)
\end{aligned}
$$

Where $\varepsilon_{\mathrm{i}}$ is the error term and $\exp \left(\varepsilon_{\mathrm{i}}\right)$ is a gamma-distributed error term with mean 1 and variance $1 / \alpha^{2} . \alpha$ is the overdispersion parameter. With the modification, the relationship between mean and variance can be expressed as

$$
\operatorname{Var}\left(\mathrm{ST}_{i}\right)=\mathrm{E}\left(\mathrm{ST}_{i}\right)\left[1+\frac{\mathrm{E}\left(\mathrm{ST}_{i}\right)}{\alpha}\right]=\mu_{i}\left(1+\frac{\mu_{i}}{\alpha}\right)
$$

Where $\mathrm{E}\left(\mathrm{ST}_{\mathrm{i}}\right)$ and $\operatorname{Var}\left(\mathrm{ST}_{\mathrm{i}}\right)$ respectively represent the mean and the variance of $\mathrm{ST}_{\mathrm{i}}$ (i.e. Store Traffic). If $1 / \alpha$ is greater than zero, the browsing data is over-dispersed. However, if $1 / \alpha$ is equal to zero (i.e. $\alpha$ is infinity), a negative binomial distribution is the same as a Poisson distribution. Therefore, the probability function of store $i$ in a time period for a negative binomial distribution can be formulated as 


$$
f\left(\mathrm{ST}_{i}\right)=\prod_{i=1}^{n} \frac{\Gamma\left(\mathrm{ST}_{i}+\alpha\right)}{\Gamma\left(\mathrm{ST}_{i}+1\right) \Gamma(\alpha)}\left(\frac{\alpha}{\mu_{i}+\alpha}\right)^{\alpha}\left(\frac{\mu_{i}}{\mu_{i}+\alpha}\right)^{\mathrm{ST}_{i}}
$$

Where $\Gamma(\cdot)$ is a gamma function. We adopt standard maximum likelihood method to estimate parameters.

\section{Store Sales Model}

Although SS is continuous variable, our data shows that many store have no transactions during the week period. This is possible for individual sellers in $\mathrm{C} 2 \mathrm{C}$ business. Estimates derived from straightforward traditional regression model and OLS method may be biased and lead to wrong results. Therefore, we apply the censored dependent variable models. The most frequently used one is the Tobit model that incorporates zero values of the dependent variable in the model in order to eliminate biases that arise from dropping such zero values. Simply stated, our sample of store sales amount, which includes both zero transactions and continuous observations, can be addressed well by estimating a Tobit model.

As in the truncation model, the dependent variable can be left-censoring, right-censoring, or both. In our data, the sales data is left-censored with clustering at a zero base since transactions may not be observed on all the stores during weekly observation period, especially for those of some small sellers or new market players. Thus, the store sales model is constructed as

$$
\begin{aligned}
S S_{j}^{*} & =\gamma X_{j}+\varepsilon_{j} \\
& =\gamma_{0}+\gamma_{1} A D_{j}+\gamma_{2} S Q_{j}+\gamma_{3} G P_{j}+\gamma_{4} R P_{j}+\gamma_{5} R P_{j} \cdot S Q_{j}+\gamma_{6} R P_{j} \cdot G P_{j}+\gamma_{7} N I_{j}+\varepsilon_{j} \\
\mathrm{SS}_{j} & = \begin{cases}S S_{j}^{*} \quad \text { if } S S_{j}^{*}>0 \\
0 \quad \text { if } S S_{j}^{*} \leq 0\end{cases}
\end{aligned}
$$

In model $5, \mathrm{SS}_{\mathrm{j}}$ represents the dependent variable (i.e. Store Sales), and $\mathrm{SS}_{\mathrm{j}}^{*}$ is a latent variable, which is observed only when the value of $\mathrm{SS}_{\mathrm{j}}$ is greater than zero. $\boldsymbol{\gamma}$ is a vector of estimable parameters associated with $\boldsymbol{X}_{j} . \gamma_{0}$ is the intercept, $\gamma_{1} \sim \gamma_{7}$ are the variable parameters respectively, and $\varepsilon_{j}$ is the error term. Hence, the likelihood function for the Tobit model over zero observations is as follows

$$
L_{\left(S S_{j}^{*}>0\right)}=\prod_{0}\left[1-\Phi\left(\frac{\gamma X_{j}}{\sigma}\right)\right] \prod_{1} \frac{1}{\sigma} \phi\left[\frac{\left(\mathrm{ss}_{j}-\gamma X_{j}\right)}{\sigma}\right]
$$

Where $\Phi()$ refers to the normal distribution function and $\varphi()$ is the normal density function. The maximum likelihood method is used to estimate the parameters. Variables of the interaction effects in model 5 were centered around the mean to diminish the nonessential multicollinearity problem (Cohen, Cohen, West \& Aiken, 2003).

\section{RESULTS}

We are interested in the cumulative effect of various marketing factors (i.e. advertising, service quality, guarantee policies, and reputation) in $\mathrm{C} 2 \mathrm{C}$ store-level on both store traffic and sales. Advertising expenses and number of shop items (control variable) are all log-transformed so the coefficient can be interpreted as elasticity. For the dependent variable - store sales, we also use log-transformation, converting it into elasticity to aid in interpretation.

We tested our hypotheses on the sample of 760 individual stores, using a negative binomial model in terms of our count dependent variable, the ST, and a Tobit regression model with the censored continuous dependent variable, the SS. In the model of ST, Model 1 (control variable-only model) as the basic model, it is the starting point for the analysis. We next incrementally add independent variables. Model 2 to Model 5 test the direct effects of advertising, service quality, guarantee policies, and store reputation on ST respectively. Model 6 is our final model to examine the effects including all the factors simultaneously. In the model of SS, aside from the steps we used for the model of ST, we also add the interaction effects of reputation with both service quality and guarantee policies, as shown in Model 7 and Model 8, respectively. The results are presented in Table 2 and Table 3, respectively. 
The regression coefficients presented in the Model 6 of ST and Model 6 of SS indicate that the relationship between store advertising and store traffic and store sales is both positive and significant traffic, which supports $\mathrm{H}_{1 \mathrm{a}}$ and $\mathrm{H}_{1 \mathrm{~b}}$. An increase in the amount of advertising expenses leads to more browsers visiting the store $(\beta=0.29, p<0.001)$, and a growth in store sales amount $(\gamma=0.27, \mathrm{p}<0.001)$. In $\mathrm{H}_{2 \mathrm{a}}$ and $\mathrm{H}_{2 \mathrm{~b}}$, we anticipate that store service will positively influence on the two dependent variables. Although the direct effect of service quality is either negative in ST model or is not significant in SS model, the full model (i.e. Model 6 in ST and Model 6 in SS) analysis results supported our assumptions that service quality exert positive and significant impacts on both ST $(\beta=0.30, p<0.05)$ and SS $(\gamma=0.69$, $\mathrm{p}<0.001)$. The results indicate that well-deserved service quality ratings can attract customers to visit stores and can increase their purchase conversion probability. Moreover, we predict that guarantee policies will have a positive effect on both ST and SS. The direct effect coefficients of guarantee policies, which in Model 4 of ST and SS respectively, presented positive and significant. However, the coefficient is neither significant in the full model (i.e. Model 6) of table $2(\beta=0.02, p>0.10)$, nor in the full model (i.e. Model 6$)$ of table $3(\gamma=0.07, p>0.10)$. Thus, we didn't find any support for $\mathrm{H}_{3 \mathrm{a}}$ and $\mathrm{H}_{3 \mathrm{~b}}$. We also posit that, as a crucial indicator, store reputation will have a positive influence on ST and SS. The coefficient of reputation is significant and positive in both Model 6 of ST $(\beta=0.31, p<0.001)$ and Model 6 of SS $(\gamma=0.23, p<0.001)$. Therefore, in strong support of $\mathrm{H}_{4 a}$ and $\mathrm{H}_{4 b}$, the stronger the store's reputation, the greater its sales amount, and the more numerous are its visitors. Furthermore, to test the effects of interaction terms ( $\left.\mathrm{H}_{5}\right)$, we add two models, Model 7 and Model 8, in the SS regression analysis. In Model 7, the interaction term between reputation and service quality was introduced. The coefficient is positive and significant $(\gamma=0.30, p<0.001)$, which supports $\mathrm{H}_{5 \mathrm{a}}$. Model 8 introduced the interaction term between reputation and guarantee policies. The results are positive and significant $(\gamma=0.07, \mathrm{p}<0.01)$, thus in support of $\mathrm{H}_{5 b}$.

Table 2. Results Explaining Store Traffic (Negative Binomial Regression Model)

\begin{tabular}{|c|c|c|c|c|c|c|}
\hline Variables & Model 1 & Model 2 & Model 3 & Model 4 & Model 5 & Model 6 \\
\hline Constant & $\begin{array}{l}2.76^{* * *} \\
(0.21)\end{array}$ & $\begin{array}{l}2.19^{* * *} \\
(0.20)\end{array}$ & $\begin{array}{l}25.67^{* * *} \\
(3.71)\end{array}$ & $\begin{array}{l}2.26^{* * *} \\
(0.22)\end{array}$ & $\begin{array}{l}1.51^{* * *} \\
(0.17)\end{array}$ & $\begin{array}{l}-2.92 \\
(1.92)\end{array}$ \\
\hline $\log (\mathrm{NP})$ & $\begin{array}{l}1.48^{* * *} \\
(0.09)\end{array}$ & $\begin{array}{l}1.45^{* * *} \\
(0.08)\end{array}$ & $1.37^{* * *}(0.09)$ & $\begin{array}{l}1.45^{* * *} \\
(0.09)\end{array}$ & $\begin{array}{l}0.56^{* * *} \\
(0.08)\end{array}$ & $\begin{array}{l}0.67^{* * *} \\
(0.08)\end{array}$ \\
\hline $\log (\mathrm{AD})$ & & $\begin{array}{l}0.47^{* * *} \\
(0.03)\end{array}$ & & & & $\begin{array}{l}0.29^{* * *} \\
(0.03)\end{array}$ \\
\hline SQ & & & $\begin{array}{l}-1.56^{* * *} \\
(0.25)\end{array}$ & & & $\begin{array}{r}0.30^{*} \\
(0.13)\end{array}$ \\
\hline GP & & & & $\begin{array}{l}0.45^{* * *} \\
(0.07)\end{array}$ & & $\begin{array}{c}0.02 \\
(0.05)\end{array}$ \\
\hline RP & & & & & $\begin{array}{l}0.37^{* * *} \\
(0.01)\end{array}$ & $\begin{array}{l}0.31^{* * *} \\
(0.02)\end{array}$ \\
\hline$\chi^{2}$ & $211.28^{* * *}$ & $468.02^{* * *}$ & $251.04^{* * *}$ & $254.21^{* * *}$ & $714.64^{* * *}$ & $817.80^{* * *}$ \\
\hline Log likelihood & -5268.50 & -5140.13 & -5248.62 & -5247.03 & -5016.82 & -4965.24 \\
\hline
\end{tabular}

$\mathrm{N}=760$. Standard errors are reported in parentheses.

${ }^{* * *} \mathrm{p}<0.001,{ }^{* *} \mathrm{p}<0.01,{ }^{*} \mathrm{p}<0.05, \dagger \mathrm{p}<0.10$. (Two-tailed test). 
Table 3. Results Explaining Store Sales (Tobit Regression Model)

\begin{tabular}{|c|c|c|c|c|c|c|c|c|}
\hline Variables & Model 1 & Model 2 & Model 3 & Model 4 & Model 5 & Model 6 & Model 7 & Model 8 \\
\hline Constant & $\begin{array}{c}0.09 \\
(0.29)\end{array}$ & $\begin{array}{c}0.26 \\
(0.28)\end{array}$ & $\begin{array}{l}-1.49 \\
(3.05)\end{array}$ & $\begin{array}{c}0.04 \\
(0.29)\end{array}$ & $\begin{array}{l}-0.26 \\
(0.27)\end{array}$ & $\begin{array}{c}-10.31^{* * *} \\
(2.89)\end{array}$ & $\begin{array}{l}1.22^{* * *} \\
(0.29)\end{array}$ & $\begin{array}{c}-8.10^{* *} \\
(2.83)\end{array}$ \\
\hline $\log (\mathrm{NP})$ & $\begin{array}{l}0.74^{* * * *} \\
(0.12)\end{array}$ & $\begin{array}{l}0.54^{* * *} \\
(0.12)\end{array}$ & $\begin{array}{l}0.75^{* * *} \\
(0.13)\end{array}$ & $\begin{array}{l}0.60^{* * *} \\
(0.12)\end{array}$ & $\begin{array}{c}0.00 \\
(0.13)\end{array}$ & $\begin{array}{c}0.05 \\
(0.12)\end{array}$ & $\begin{array}{c}0.07 \\
(0.12)\end{array}$ & $\begin{array}{c}0.05 \\
(0.12)\end{array}$ \\
\hline $\log (\mathrm{AD})$ & & $\begin{array}{l}0.42^{* * * *} \\
(0.05)\end{array}$ & & & & $\begin{array}{l}0.27^{* * *} \\
(0.05)\end{array}$ & $\begin{array}{l}0.24^{* * * *} \\
(0.05)\end{array}$ & $\begin{array}{l}0.25^{* * * *} \\
(0.05)\end{array}$ \\
\hline SQ & & & $\begin{array}{c}0.11 \\
(0.20)\end{array}$ & & & $\begin{array}{l}0.69^{* * *} \\
(0.19)\end{array}$ & $\begin{array}{l}0.50^{*} \\
(0.20)\end{array}$ & $\begin{array}{l}0.65^{* * * *} \\
(0.19)\end{array}$ \\
\hline GP & & & & $\begin{array}{l}0.33^{* * *} \\
(0.07)\end{array}$ & & $\begin{array}{c}0.07 \\
(0.07)\end{array}$ & $\begin{array}{c}(0.20) \\
0.09 \\
(0.06)\end{array}$ & $\begin{array}{c}0.06 \\
(0.07)\end{array}$ \\
\hline $\mathrm{RP}$ & & & & & $\begin{array}{l}0.27^{* * *} \\
(0.02)\end{array}$ & $\begin{array}{l}0.23^{* * *} \\
(0.03)\end{array}$ & $\begin{array}{l}0.23^{* * *} \\
(0.03)\end{array}$ & $\begin{array}{l}0.24^{* * *} \\
(0.03)\end{array}$ \\
\hline $\mathrm{RP} \cdot \mathrm{SQ}$ & & & & & & & $\begin{array}{l}0.30^{* * *} \\
(0.07)\end{array}$ & \\
\hline $\mathrm{RP} \cdot \mathrm{GP}$ & & & & & & & & $\begin{array}{l}0.07^{* *} \\
(0.02)\end{array}$ \\
\hline$\chi^{2}$ & $35.28^{* * *}$ & $111.67^{* * *}$ & $35.55^{* * *}$ & $58.23^{* * *}$ & $158.29^{* * *}$ & $204.00^{* * *}$ & $222.33^{* * *}$ & $213.42^{* * *}$ \\
\hline $\begin{array}{l}\text { Log } \\
\text { likelihood }\end{array}$ & -1328.82 & -1290.63 & -1328.68 & -1317.34 & -1267.31 & -1244.46 & -1235.29 & -1239.75 \\
\hline
\end{tabular}

$\mathrm{N}=760$. Standard errors are reported in parentheses.

$* * * \mathrm{p}<0.001, * * \mathrm{p}<0.01, * \mathrm{p}<0.05, \dagger \mathrm{p}<0.10$. (Two-tailed test).

Obs. Summary: 203 left-censored observations at $\log (\mathrm{SS}) \leq 0 ; 557$ uncensored observations; 0 right-censored observations.

\section{DISCUSSION}

This article highlights two crucial drivers of online business performance: store traffic and store sales. We use real market data from a major Chinese $\mathrm{C} 2 \mathrm{C}$ platform to examine how various marketing factors as antecedents influence ST and SS. We adopt Negative Binomial model for ST and Tobit regression model for SS respectively. The results are in accordance with our hypotheses that advertising, store service quality, as well as store reputation have positive effects on both ST and SS. However, when we control all variables in our full models, we find that guarantee policies have no effect on either ST or SS. In addition, we find strong interaction effects of store reputation with service quality and guarantee policies on SS.

\section{Implications}

Previous research investigating customer online browsing behaviors were mainly based on clickstream data set, and constructed explanatory facets depending on people's within-site viewing behavior itself (Moe, 2003; Montgomery et al., 2004; Bucklin \& Sismeiro, 2003). Our study attempted to take part in this discussion and add supplementary information and insight.

First, instead of adopting within web page viewing behavior data, we chose to use exogenous data to explain online shoppers' browsing behavior. We tested how various external influences can impact customers' visiting a particular online store. Second, owing to the consideration of the overdispersion of our count data, we adopted Negative Binomial model instead of Poisson model for ST analysis. It was found that Negative Binomial model is more superior based on analyzing infrequently event data, to which we included visitors who accessed the store's front page and then exited. In terms of online store sales, previous studies demonstrated that store service (e.g. Pan, Ratchford \& Shankar, 2002; Choi, Chow, Kwok, Liu \& Shen, 2013), guarantee policies (e.g. Karimov \& Brengman, 2014; Fan, Miao \& Wu, 2013; Bower \& Maxham, 2012), and reputation (e.g. Ye, Li, Kiang \& Wu, 2009; Melnik \& Alm, 2002), each determinant separately can influence online store performance. However, in real transactions, customers usually put all factors together for their consideration before making a decision. Thus, in our study, we analyzed various facets simultaneously and examined their cumulative effects. Interestingly, though previous studies have found that guarantee policies positively effect on sales, we found that when control for other marketing factors, the positive effect of guarantee policies was negligible. It implies that customers may evaluate each marketing factor as not equal when 
deciding in which store to buy. Accordingly, our results have shown a strong positive and significant interaction effect between reputation and guarantee policies on sales. This finding helps verify the different weight effect of various factors. In addition, some of the prior articles used OLS as model estimating method for C2C store sales (e.g. Ye et al., 2009). However, since the real transaction data may contain many zero values and may have truncated problems, OLS method will over-estimate the mean and bias the results. Thus, we adopted Tobit model and maximum likelihood estimating method in our analysis.

Our results offered performance tips in terms of managerial implications for online with respect to both ST and SS as well. First, even though advertising expense is a heavy burden for $\mathrm{C} 2 \mathrm{C}$ sellers, we provide empirical evidence that investments in advertising are indeed important to the growth of ST and SS, especially in attracting customers to browse their stores. Second, our finding reveals the importance of $\mathrm{C} 2 \mathrm{C}$ sellers in understanding the different weight effect of various marketing factors. Although consumers are dedicated to evaluating every piece of information at hand before making a purchase decision, they are usually not assessed equally. For instance, a store's guarantee policies is regarded as a major determinant of attracting browsers and increasing sales by many managers and scholars. This is true when provide guarantee policies as the only indicator of store to customers. However, if a buyer evaluates all factors together, the positive effect of guarantee policies disappears. The other example is that, although store service quality proves to be a statistically significant determinant, which indicates that a seller with a better service quality can expect to receive a higher ST, its impact tends to be small. This evidence implies that when a store has a high conversion rate but a low visit rate, the seller should make more effort on upgrading their reputation and investing more money on store advertising, not necessarily paying as much attention on service quality or guarantee policies. But when a store aims to increase conversion rate, the seller should bear in mind that it is a crucial quality and performance for a competitive $\mathrm{C} 2 \mathrm{C}$ store to have a high service quality at least.

\section{Limitations and Future Research}

The current research poses several restrictions on areas of study that have room for improvements in future opportunities. First, our data was contained to only a snapshot of $\mathrm{C} 2 \mathrm{C}$ business at one product category in a random single week. However, consumers' online behaviors are a dynamic and complex course. We need panel data to make our observations and results more dynamic and robust. Second, we didn't control for potential endogeneity in our models. Future research with elaborate methods will provide the means a more in depth study. Third, the comparison of other influential factors (e.g. in-store promotion or discount), and the analysis of $\mathrm{C} 2 \mathrm{C}$ stores across various product categories will also allow us to gain additional understanding into the distinctions between the relative impacts of the antecedents on ST and SS.

\section{AUTHOR BIOGRAPHIES}

Zheng Wang (the first author), is a Ph.D. Candidate of Management (Marketing Concentration) at SungKyunKwan University, South Korea. He is also a Lecturer in School of Business Administration in Qilu University of Technology, China. Address: Building A of Guanghua School of Management, Peking University, 5 Yiheyuan Rd., Haidian District, Beijing, P.R. China, 10087. Email: zheng.wang@pku.edu.cn

Yongjune Kim (corresponding author), is a Professor of Business School, and he is also the Dean of Graduate School of China (GSC) at SungKyunKwan University, South Korea. He holds his Ph.D. in Management (Marketing Concentration) from Kellogg School of Management at Northwestern University, US. Address: Graduate School of China, International Building, SungKyunKwan University, 25-2, Sungkyunkwan-Ro, Jongno-Gu, Seoul, Korea, 03063. Email: kimyj@skku.edu

\section{REFERENCES}

Amyx, D.A. \& Luehlfing, M.S. (2006). Winners curse and parallel sales channels—online auctions linked within e-tail websites. Information \& Management, 43(8), 919-927.

Anderson, \& Srinvasan, S. (2010). E-satisfaction and e-loyalty: A contingency framework. Psychology Marketing, 20(2), 123138.

Anderson, R. E., Swaminathan, S. \& Mehta, R. (2013). How to drive customer satisfaction. MIT Sloan Management Review, 
54(4), 13-15.

Ba, S. \& Pavlou, P. (2002). Evidence of the effect of trust building technology in electronic markets: Price premiums and buyer behavior. MIS Quarterly, 26(3), 243-268.

Babakus, E., Bienstock, C. C. \& Scotter, J. R.V. (2004). Linking perceived quality and customer satisfaction to store traffic and revenue growth. Decision Sciences, 35(4), 713-737.

Bellman, G., Lohse, J. L. \& Johnson, E. J. (1999). Predictors of online buying behavior. Communications of the ACM, 42(12), 32-38.

Boshoff, C. \& Staude, G. (2003). Satisfaction with service recovery: Its measurement and its outcomes. South African Journal of Business Management, 34(3), 9-16.

Bower, A. B. \& Maxham, J. G. (2012). Return shipping policies of online retailers: Normative assumptions and the long-term consequences of free and free returns. Journal of Marketing, 76(5), 110-124.

Bruce, N., Murthi, B. P. S. \& Rao, R. C. (2017). A dynamic model for digital advertising: The effects of creative formats, message content and targeting on engagement. Journal of Marketing Research, 54(3), 202-218.

Bucklin, R. \& Sismeiro, C. (2003). A model of website browsing behavior estimated on clickstream data. Journal of Marketing Research, 40(3), 249-267.

Cachon, G. P., Terwiesch, C. \& Xu, Y. (2008). On the effects of consumer search and firm entry in a multiproduct competitive market, Marketing Science, 27(3), 461-473.

Chen, J., Zhang, C. \& Xu, Y. (2009). The role of mutual trust in building members loyalty to a C2C platform provider. International Journal of Electronic Commerce, 14(1), 147-171.

Chen, Y. H., \& Barnes, S. (2007). Initial trust and online buyer behavior. Industrial Management \& Data Systems, 107(1), $21-36$.

Choi, T. M., Chow, P. S., Kwok, B., Liu, C. S. \& Shen, B. (2013). Service quality of online shopping platforms: A case-based empirical and analytical study. Mathematical Problems in Engineering, 2013(3), 841-860.

Chow, W. S. \& Angie, N. K. (2006). A study of trust in e-shopping before and after first-hand experience is gained. Journal of Computer Information Systems, 66(4), 125-130.

Chu, H. \& Liao, S. L. (2008). Toward a conceptual model of consumer online resale behavior: An exploratory study in Taiwan. Journal of Internet Commerce, 7(2), 220-252.

CNNIC Annual Report (2015). China Internet Network Information Center, 2015 Annual Report, available at http://www.cnnic.cn/gywm/zzkw/cnnicndbg/201612/P020161212477199557985.pdf (Accessed on Aug. 16 ${ }^{\text {th }}, 2016$ ).

Cohen, J, Cohen, P., West, S. G. \& Aiken, L. S. (2003). Applies multiple regression/correlation analysis for the behavioral sciences (3rd Ed.), Lawrence Erlbaum Associates: Mahwah, NJ.

Dellarocas, C. (2003). The digitization of word of mouth: Promise and challenges of online feedback mechanisms. Management Science, 49(10), 1407-1424.

Deng, Z. H., Zheng, W. L. \& Qin, J. C. (2014). Empirical Study on the comprehensive evaluation of e-service quality in Chinese C2C markets. Journal of Applied Statistics \& Management, 4, 604-619.

Fan, Y. W., Miao, Y. F. \& Wu, S. C. (2013). Customer complaints and service policy in electronic commerce. South African Journal of Business Management, 44(3), 15-20.

Forbes, L. P., Kelley, S. W. \& Hoffman, K. D. (2005). Typologies of e-commerce retail failures and recovery strategies. Journal of Services Marketing, 19(5), 280-292.

Forrester Report (2015). Forrester Research E-commerce Forecast, 2014-2019, available at www.forrester.com/Forrester+Research+eCommerce+Forecast+2014+To+2019+US/fulltext/-/E-res116713 (Accessed on Dec. 10th, 2015)

Gijsbrechts, E., Campo, K. \& Goossens, T. (2003). The impact of store flyers on store sales and store traffic: A geomarketing approach. Journal of Retailing, 79(1), 1-16.

Hennig Thurau, T. \& Walsh, G. (2003). Electronic word-of-mouth: Motives for and consequences of reading customer articulations on the internet. International Journal of Electronic Commerce, 8(2), 51-74.

Jerry, H., Bronwyn, H. \& Griliches, Z. (1984). Economic models for count data with an application to the patents-R\&D. Econometrica, 52(4), 909-938.

Jones, K. \& Leonard, L. N. K. (2014). Factors influencing buyers trust in consumer-to-consumer e-commerce. Journal of Computer Information Systems, 54(4), 71-79.

Karimov, F. P. \& Brengman, M. (2014). An examination of trust assurances adopted by top internet retailers: Unveiling some critical determinants. Kluwer Academic Publishers, 2014(14), 459-496.

Long, J.S. (1997). Regression models for categorical and limited dependent variables. Sage Publications, Inc., Thousand Oaks, CA US.

Mcdonald, C. G. \& Slawson, C. V. (2002). Reputation in an internet auction market. Economic Inquiry, 40(4), 633-650.

Melnik, M. I. \& Alm, J. (2002). Does a sellers e-commerce reputation matter? Evidence from eBay auctions. The Journal of Industrial Economics, 50(3), 337-349.

Moe, W. W. (2003). Buying, searching, or browsing: Differentiating between online shoppers using in-store navigational clickstream. Journal of Consumer Psychology, 13(1), 29-39.

Montgomery, A., Li, S., Srinivasan, K. \& Liechty, J. C. (2004). Modeling online browsing and path analysis using Clickstream data. Marketing Science, 23(4), 579-595. 
Pan, X., Ratchford, B. T. \& Shankar, V. (2002). Can price dispersion in online markets be explained by differences in e-tailer service quality? Journal of the Academy of Marketing Science, 30(4), 433-445.

Pan, Y. \& Zinkhan, G. M. (2006). Antecedents of retail patronage: A meta-analytical perspective. Journal of Retailing, 82(3), 229-243.

Pavlou, P. A., Liang, H. \& Xue, Y. (2007). Understanding and Mitigating Uncertainty in Online Exchange Relationships: A principal-agent perspective. Social Science Electronic Publishing, 31(1), 105-136.

Resnick, P., Zeckhauser, R., Friedman, E. \& Kuwabara, K. (2000). Reputation systems. Communication of the ACM, 43(12), 4548.

Sahni, N. S. (2016). Advertising spillovers: Evidence from Online field experiments and implications for returns on advertising. Journal of Marketing Research, 53, 459-478.

Stafford, M. R. \& Stern, B. (2002). Consumer bidding behavior on internet auction sites. International Journal of Electronic Commerce, 7(1), 135-150.

Udo, G. J., Bagchi, K. K. \& Kirs P. J. (2010). An assessment of customers e-service quality perception, satisfaction and intention. International Journal of Information Management, 30(6), 481-492.

Vishwanath, A., \& Barnett, G. A. (2005). An empirical investigation into the structure of bidding in online auctions, Electronic Markets, 15(3), 261-268.

Ward, S. G., \& Clark, J. M. (2014). Bidding behavior in on-line auctions: An examination of the eBay Pokemon card market. $M$. E. Sharpe, Inc. 6(4), 139-155.

Wu, K., Vassileva, J., Noorian, Z. \& Zhao, Y. (2015). How do you feel when you see a list of prices? The Interplay among price dispersion, perceived risk and initial trust in Chinese C2C market. Journal of Retailing \& Consumer Services, 25, 3646.

Wu, K., Vassileva, J., Zhao, Y., Noorian, Z., Waldner, W. \& Adaji, I. (2016). Complexity or simplicity? Designing product pictures for advertising in online marketplaces. Journal of Retailing \& Consumer Services, 28, 17-27.

Xu, B., Lin, Z. X. \& Shao, B. J. (2010). Factors affecting consumer behaviors in online buy - it - now auctions. Internet Research, 20(5), 509-526.

Ye, Q., Li, Y., Kiang, M. \& Wu, W. (2009). The impact of seller reputation on the performance of online sales: Evidence from TaoBao buy-it-now (BIN) data. ACM SIGMIS Database, 40(1), 12-19.

Zhao, Z. B., Sun, L. P. \& Su, M. (2012). How to increase online visits and sales? An empirical study on the consumer-toconsumer online stores. 2012 International Joint Conference on Service Sciences, Shanghai, 2012, 130-133. 


\section{ENDNOTE}

The calculation of seller's service score is based on every successful transaction and is given by buyers. It is a dynamic indicator depending on the average score of buyers' rating in last six months. As criteria of the $\mathrm{C} 2 \mathrm{C}$ platform, the initial default score of seller's service quality starts from 15. In this case, there are two situations if service score maximum: a seller satisfied all past buyers with gaining full ratings, and a seller has no successful transactions with keeping the initial default scores. We believe that the stores which attributes to zero sales amount and full service scores stand for the "zombie shops" and are not suitable for the purpose of this study. 